\title{
Ripple Effect of Housing Prices among Chinese Deputy Provincial Cities Based on an Alternative Approach
}

\author{
Feixue Huang (Corresponding author) \\ Economics School, Faculty of Management and Economics, Dalian University of Technology \\ 2 Ling Gong Road, Dalian 116024, China \\ Tel: 86-411-84707210Ｅ-mail: huangfeixue@yahoo.cn \\ Cheng Li \\ Economics School, Faculty of Management and Economics, Dalian University of Technology \\ 2 Ling Gong Road, Dalian 116024, China \\ Tel: 86-411-84707210Ｅ-mail: lchengzi2008@yahoo.com.cn \\ Yanxi Li \\ Economics School, Faculty of Management and Economics, Dalian University of Technology \\ 2 Ling Gong Road, Dalian 116024, China \\ Tel: 86-411-84707210Ｅ-mail: mrliyx@dlut.edu.cn
}

Received: March 25, $2010 \quad$ Accepted: November 1,2010 DOI: 10.5430/ijba.v1n1p19

The research is financed by the funds project under the National Science Foundation under Grant No. 70772087\&70903011; the Ministry of Education of the PRC for young people who are devoted to the researches of humanities and social sciences under Grant No. 09YJC790025; the Fundamental Research Funds for the Central Universities under Grant No. DUT10ZD107.

\begin{abstract}
This paper applies a two-stage procedure of non-parametric testing and business cycle dating techniques to examine the ripple effect of housing prices among Chinese cities since 2006. Empirical analysis indicates that housing prices fluctuations among nineteen Chinese cities do have ripple effect. We divide the cities into three layers: Shenzhen and Guangzhou are in the first layer; Beijing, Shanghai, Hangzhou, Nanjing, Xiamen are in the second; and other cities are in the third one. The direction is from the first layer to the third layer and the effect gets weaker and weaker. Empirical results show that: (1) Shenzhen and Guangzhou are the main regulatory targets; (2) Cities in the second layer should be paid attention to, especially unexpected fluctuations of housing prices of cities in the third layer ought to be avoided.
\end{abstract}

Keywords: House prices, Ripple effect, Non-parametric test of ranking, Business cycle dating techniques

\section{Introduction}

Since the reform of China's real estate, China's housing prices are soaring up quickly. Especially after 2005, in China's Beijing, Shanghai, Shenzhen, Guangzhou and other cities, housing prices are so high that people are hard to afford houses. In 2010, housing prices of Beijing, Hangzhou, Shanghai and other tier-one cities increased by $20 \%$ based on late 2009. The overall housing price increase of major cities is $39 \%$ relative to January 1,2009 , of which housing prices in tier-one cities increased by $53 \%$ and tier-two cities increased by $23 \%$. As housing prices in major cities are too high, people's housing demand is inhibited, which leads to population outflow, and eventually it will stabilize local housing price and cause outward extension of high waves of housing prices, that is housing prices of tier-two and tier-three cities increasing. As a result ripple effect of housing prices appears.

Foreign scholars do researches on regional housing price fluctuations effect using a number of approaches: Meen (1999) suggested that structural differences in regional housing markets were important. A new model of house prices for the regions in Great Britain was devised and estimated in which the coefficients exhibited non-random spatial patterns. The 
coefficients reflected structural differences between the regions and it was shown, through simulations, that the model could generate a ripple effect irrespective of regional growth patterns. Cook (2003) examined the possibility of a ripple effect being present in the UK housing market using a previously unconsidered two-stage procedure. The results showed the ripple effect hypothesis that changed in house prices occurred earlier and more extensively in the South East of England than in other regions of the UK. Berry and Dalton (2004) argued that population density, immigration speed, and geographic location were the main factors leading to house price fluctuations in the view of area coverage. Cook (2005) discovered that the notion of a ripple effect in the UK housing market implied stationarity in regional: national house price ratios. A new means of examining this issue was proposed which involved the joint application of a powerful unit root test and a test of stationarity. Holmes (2007) offered a novel approach through the application of unit root testing within a seemingly unrelated regression framework. He argued that there existed significant advantages in this approach over and above existing univariate and panel data unit root testing procedures. The results indicated that the majority of UK regions exhibited regional house price convergence. However, there was an east-west split in terms of whether regional house prices had a tendency towards long-run equilibrium relationship with UK prices as whole. Zhen Q. L., etc. (2007) developed an innovative approach to quantitatively examine the diffusion patterns of house prices in mega-cities of a country. The results showed that a 1-1-2-4 diffusion pattern existed within these cities. Sydney was on the top tier with Melbourne in the second; Perth and Adelaide were in the third level and the other four cities lied on the bottom. Larraz-Iribas and Alfaro-Navarro (2008) investigated regional housing prices in Spain using variable co-integration techniques. It analyzed the asymmetric behavior in real house prices among the Spanish regions. Song S., etc (2009) examined local house price co-movements by using various house price indexing approaches. They found in the long run that the ripple effect was most likely constrained within regions. The results supported the theory that the ripple effect was likely to be caused by a region's internal economic factors rather than migration and spatial arbitrage. Foreign studies are based on foreign markets. Because real estate has strong regional characteristics so their results can not be suitable for Chinese condition.

Domestic researches on real estate price were mainly concentrated in the relationship with various regions. Representative researches are as follows: Gu W. (2005) applied micro-economics theory to compare Shanghai with United States in real estate price. The results showed that house price in Shanghai had exceeded the average house price in United States and it was more than house prices of New York and Chicago, so they brought up the idea that house price in Shanghai had been overheating. Pi Shun and Wu K.p. (2006) found that there was two-way linear Granger Causality between the real estate market and financial market of China, but not nonlinear Granger Causality. Liang Y.f. and Gao T.m (2007) dynamically analyzed the factors, which determined real estate price fluctuation, based on error correction model and panel data model. In these models, they considered the impact of monetary policy on house price specially. They suggested that relevant departments could take policies according to local conditions in order to effectively control the increase of house prices. Wang Song-tao, Yang Zan, Liu H.y. (2008) applied "ripple effect" theory and used Johansen cointegration test, multivariable Granger causality test and impulse response function method to analyze the interaction of house price among China's five major regional markets but because of data limitations not all related variables were included in regional house price model. Domestic researches on real estate price can not include all the related variables to the model because of data limitations, or researchers are less in studying the ripple effect of housing prices with lack of corresponding empirical methods.

In sum, there are not enough domestic researches on the ripple effect of housing prices. This paper adopted an alternative two-stage approach proposed by Cook (2003) which is non-parametric tests of ranking and business cycle dating techniques to examine the ripple effect of housing prices among China's 19 cities in recent years. In the first stage non-parametric testing is used to investigate different housing prices fluctuations in different cities and in the second stage business cycle dating techniques are employed to discover the cities where housing prices first start to fluctuate, so it can prove that the ripple effect of housing prices exists in China's cities.

\section{Non-parametric testing of housing price volatility}

From Figure 1 we see that in the last three years the national housing prices fluctuated considerably, especially from January, 2008 to March, 2009, the national real estate selling price index continued to decline from the highest point to the lowest, but from March, 2009 up to now it is gradually increasing, so the period in which we research is divided into two parts: from January, 2008 to March, 2009 and from March, 2009 to April, 2010, and we adopt Friedman non-parametric test of ranking to examine housing price volatility.

This part selects monthly real estate selling price indexes of 19 cities in China from January 2008 to April 2010. These cities include 4 municipalities: Beijing, Shanghai, Tianjin, Chongqing and 15 deputy provincial cities: Wuhan, Chengdu, Xi'an, Haerbin, Changchun, Shenyang, Dalian, Jinan, Qingdao, Nanjing, Hangzhou, Ningbo, Xiamen, Guangzhou, 
Shenzhen. Data are all obtained from "China Price Yearbook" and web site of National Statistics Bureau of China (www. stats. gov. cn).

We get the nature logs of all data. Each variable is named after the first letter of Pinyin name of each city shown as follows: Beijing $(\ln b j)$, Shanghai $(\ln s h)$, Tianjin $(\ln t j)$, Chongqing $(\ln c q)$, Wuhan $(\ln w h)$, Chengdu $(\ln c d)$, Xi'an $(\ln x a)$, Haerbin(lnheb), Changchun(lncc), Shenyang(lnsy), Dalian(lndl), Jinan(lnjn), Qingdao(lnqd), Nanjing $(\ln n j)$, Hangzhou(lnhz), Ningbo(lnnb), Xiamen $(\ln x m)$, Guangzhou(lngz), Shenzhen $(\ln s z)$.

To examine whether the volatility of house prices differs across the 19 cities of China, Friedman's non-parametric test of ranking is employed using $\left|\Delta p_{t}\right|$, as a measure of volatility, where $p_{t}$ is the natural logarithm of housing prices. In each period, the cities are ranked according to the observed value of $\left|\Delta p_{t}\right|$, with the ranking 1 awarded to the city with the smallest value and 19 awarded to the city with the greatest. To examine whether any observed difference in ranking is significant statistically throughout the sample period, the Friedman test statistic $(F r)$ is calculated as below:

$$
F r=\left[\frac{12}{T(k)(k+1)} \sum_{j=1}^{k} S_{j}^{2}\right]-3 T(k+1)
$$

Where $T$ denotes the number of observations, $\mathrm{k}$ denotes the number of cities and $S_{j}^{2}$ denotes the sum of squared rankings for city $\mathrm{j}$. To illustrate the variation in house price volatility, Table 1 presents an ordered sequence of the sums of ranks $\left(S_{j}^{2}\right)$ for the cities of China.

The paper calculated the sums of ranks of 19 cities in China in two periods that are housing prices declining stage from January 2008 to March 2009 and housing prices rising stage from March 2009 to April 2010. Table 1 presents an ordered sequence of the sums of ranks $\left(S_{j}^{2}\right)$ for the cities of China. From inspection of Table 1 it is clear that Shenzhen tends to exhibit greatest volatility and in housing prices declining stage Shenzhen, Chongqing and Beijing have greater volatility, while in housing prices rising stage Shenzhen, Guangzhou, Hangzhou show lager volatility. We continue to analyze Table 1, and then Table 2 is available. Table 2 reveals the rank changes in two periods for each city.

Table 2 shows that housing price of some popular cities have greater volatility in rising stage, while other relatively less active cities' housing prices are more likely to fluctuate in declining stage. In housing declining stage Guangzhou ranked 5 while in rising stage it ranked 18, so it can be found that housing price of Guangzhou is easy to increase, on the contrary housing prices of Ningbo is more likely to decline. Jinan and Beijing's ranks in housing prices declining stage and rising stage have little change, namely the fluctuations of them in the two periods are about the same. And in general it is clear that Shenzhen, Hangzhou, Beijing, Guangzhou and Nanjing are the most active cities, which can be observed from the test which is examined from January 2008 to April 2010.

To examine whether this increased volatility is significant, the $F r$ statistic can be compared to a $\chi_{k-1}^{2}$ critical value. In housing prices declining stage the calculated $F r$ statistic is 45.162 ; in housing prices rising stage $F r$ is 64.659 ; in the period from January 2008 to April $2010 \mathrm{Fr}$ is 77.469 . It shows that the hypothesis of equal volatility across cities is comfortably rejected with a p-value of 0.005 .

\section{Dating turning points in China housing prices}

With increased volatility detected in house prices in some popular cities, the next stage in analyzing the ripple effect is to examine whether changes in house prices are observed in popular cities before other cities. The business cycle dating techniques of Birchenhall, etc (2001) are employed to examine whether peaks and troughs of housing prices across cities occur at different times.

Quarterly real estate selling price indexes of 19 cities in China are selected from first quarter of 2008 to first quarter of 2010. These cities also include 4 municipalities: Beijing, Shanghai, Tianjin, Chongqing and 15 deputy provincial cities: Wuhan, Chengdu, Xi'an, Haerbin, Changchun, Shenyang, Dalian, Jinan, Qingdao, Nanjing, Hangzhou, Ningbo, Xiamen, Guangzhou and Shenzhen. Data are all obtained from web site of National Statistics Bureau of China (www. stats. gov. $\mathrm{cn})$.

The decision rules used to determine whether a peak or trough is observed are given in Table 3. It can be seen that a peak is identified if the value in a particular period is greater than values in the following two quarters, while also being at least as large as other values in the preceding and subsequent two years. Table 3 also shows that the reversal of these rules allows the dating of troughs. The results of applying these dating rules to cities' housing prices are presented in Table 4.

As can be seen from Table 4, a peak of housing prices is first observed in the fourth quarter of 2006 in Guangzhou, followed by the next peak occurring in Shenzhen, and Jinan is the final city to exhibit a peak occurring in the first quarter of 2008. For troughs, Guangzhou, Chongqing are the first cities to experience troughs in the 3rd quarter of 2008, 
followed by Shenzhen and other cities, while Shenyang is the final city to exhibit troughs in the 4th quarter of 2009. Therefore, it shows that Guangzhou, Shenzhen and some other popular cities experience peaks and troughs before other cities, as suggested by the ripple effect.

\section{Analysis on empirical results}

This paper examines the possibility of a ripple effect being present in the Chinese cities' housing prices using Friedman non-parametric testing and business cycle dating techniques, thus it provides basis for the rational regulations of Chinese cities' housing selling price. Through results of two-stage method we can divide 19 cities into three layers.

Shenzhen and Guangzhou are in the first layer, because in the first stage of analysis, Shenzhen and Guangzhou rank back for their housing prices have greatest fluctuations and in the second stage housing prices of Shenzhen and Guangzhou experience peaks and troughs earlier, from which it can be determined that these two cities are in the first layer of the ripple effect. Shenzhen is the China's first Special Economic Zone and Guangzhou is called China's "South Gate". The two cities have superior geographical location, well-developed foreign trade and rapid population mobility, so their housing prices are most sensitive to changes and they have great radiometric force.

Beijing, Shanghai, Hangzhou, Nanjing and Xiamen are in the second layer. Although their housing prices fluctuations are not as great as that in Shenzhen and Guangzhou, they are cities with well-developed economy and power of influence, housing prices of which also fluctuate early and are able to affect housing prices in other cities. Finally the remaining 12 cities are classified as the third layer, for the reason that compared with the previous two layer, their housing prices fluctuations are relatively weak and late.

Therefore, after dividing China's 19 deputy provincial cities into three layers, it can clear be seen that the ripple effect of housing prices in China is obvious and regular, so that it has positive significance for monitoring housing prices and establishing relevant policies.

\section{Conclusions and suggestions}

\subsection{Shenzhen and Guangzhou are the main regulatory targets}

It can be drawn from previous analysis that Shenzhen and Guangzhou are in the first layer with great and rapid housing prices fluctuations, therefore, regulating their housing prices will play a significant role on controlling the whole system's housing prices. However it needs to adjust and control housing prices to the point according to the cities' geographical characteristics and radiation scopes.

5.2 Cities in the second layer should be paid attention to, especially unexpected housing prices fluctuations of cities in the third layer ought to be avoided

Beijing, Shanghai, Hangzhou and other cities in the second layer always have higher housing prices. However, the results find that although these cities are not in the first layer of the ripple effect which may be related to their relative independence, but they as the cities in second layer still have strong volatility. Therefore, their housing prices need to be paid great attention to.

Jinan, Shenyang, Wuhan and other inland cities belong to the third layer. They are the last cities where the ripple effect transfers to. These cities should adopt flexible regulatory policies to avoid unexpected fluctuations in housing prices so as to achieve the stability of housing prices in the whole system.

\section{References}

Berry, M., and Dalton, T. (2004). House Prices and the Policy Dilemmas: A Peculiarly Australia Problems? Urban Policy and Research, 22, 69-91.

Birchenhall, C. R., Osborn, D. R., \& Sensier, M. (2001). Predicting UK Business Cycle Regimes. Scottish Journal of Political Economy, 48, 179-195.

Cook, S., and Thomas, C. (2003). An Alternative Approach to Examining the Ripple Effect in UK House Prices. Applied Economics Letters, 10, 849-851.

Cook, S. (2005). Regional House Price Behaviour in the UK: Application of a Joint Testing Procedure. Physica A: Statistical Mechanics and its Applications, 345, 611-621.

Gu, W. (2005). Comparative study on Housing Prices of Shanghai and USA. Price: Theory \& Practice, 1, 50-51.

Holmes, M. J. (2007). How Convergent are Regional House Prices in the United Kingdom? Some New Evidence from 
Panel Data Unit Root Testing. Journal of Economic and Social Research, 9, 1-17.

Larraz-Iribas, B., and Alfaro-Navarro, J-Luis (2008). Asymmetric Behaviour of Spanish Regional House Prices. International Advances in Economic Research, 14, 407-421.

Liang, Y. f., and Gao, T. m. (2007). Empirical Analysis on Real Estate Price Fluctuation in Different Provinces of China. Economic Research Journal, 8, 133-142.

Luo, Zh. q., LIU, Ch. 1., and Picken, D. (2007). Housing Price Diffusion Pattern of Australia's State Capital Cities. International Journal of Strategic Property Management, 11, 227-242.

Meen, G. (1999). Regional House Prices and the Ripple Effect: A New Interpretation. Housing Studies, 4, 733-753.

Pi, Sh., and Wu K. p. (2006). Chinese Research to the Development Relationship between Real Estate Market and Finance Market. Journal of Industrial Engineering and Engineering Management, 20, 1-6.

Song, S., Young, M., and Hargreaves, B. (2009). The Ripple Effect of Local House Price Movements in New Zealand. Journal of Property Research, 26, 1-24.

Wang, S. t., Yang, Z., and Liu H.y. (2008). Empirical Research on the Interactive Relationship among Housing Prices in China's Regional Market. Research on Financial and Economic Issues, 6, 122-129.

Table 1. Sums of ranks

\begin{tabular}{|c|c|c|c|c|c|c|c|c|}
\hline \multicolumn{2}{|c|}{$2008.1-2009.3$} & \multicolumn{2}{c|}{$2009.3-2010.4$} & \multicolumn{3}{c|}{$2008.1-2010.4$} \\
\hline City & $S_{i}$ & rank & City & $S_{i}$ & rank & City & $S_{i}$ & rank \\
\hline Tianjin & 82 & 1 & Haerbin & 60 & 1 & Haerbin & 182 & 1 \\
\hline Dalian & 98 & 2 & Shenyang & 73 & 2 & Shenyang & 198 & 2 \\
\hline Jinan & 107 & 3 & Ningbo & 82 & 3 & Tianjin & 199 & 3 \\
\hline Qingdao & 109 & 4 & Jinan & 95 & 4 & Jinan & 202 & 4 \\
\hline Guangzhou & 121 & 5 & Chengdu & 108 & 5 & Dalian & 212 & 5 \\
\hline Haerbin & 122 & 6 & Dalian & 114 & 6 & Qingdao & 234 & 6 \\
\hline Shanghai & 124 & 7 & Tianjin & 117 & 7 & Ningbo & 242 & 7 \\
\hline Shenyang & 125 & 8 & Changchun & 118 & 8 & Wuhan & 253 & 8 \\
\hline Wuhan & 130 & 9 & Wuhan & 123 & 9 & Chengdu & 253 & 8 \\
\hline Xiamen & 133 & 10 & Qingdao & 125 & 10 & Shanghai & 267 & 10 \\
\hline Hangzhou & 144 & 11 & Chongqing & 126 & 11 & Changchun & 271 & 11 \\
\hline Nanjing & 145 & 12 & Xi'an & 138 & 12 & Xiamen & 280 & 12 \\
\hline Chengdu & 145 & 12 & Shanghai & 143 & 13 & Chongqing & 302 & 13 \\
\hline Changchun & 153 & 14 & Xiamen & 147 & 14 & Xi’an & 304 & 14 \\
\hline Ningbo & 160 & 15 & Beijing & 150 & 15 & Nanjing & 310 & 15 \\
\hline Xi’an & 166 & 16 & Nanjing & 165 & 16 & Guangzhou & 310 & 15 \\
\hline Beijing & 171 & 17 & Hangzhou & 183 & 17 & Beijing & 321 & 17 \\
\hline Chongqing & 176 & 18 & Guangzhou & 189 & 18 & Hangzhou & 327 & 18 \\
\hline Shenzhen & 241 & 19 & Shenzhen & 210 & 19 & Shenzhen & 451 & 19 \\
\hline
\end{tabular}


Table 2. Analysis on rank changes between housing prices rising stage and declining stage

\begin{tabular}{|c|c|c|c|}
\hline \multirow{2}{*}{$\begin{array}{l}\text { Cities ranks of which } \\
\text { in housing prices } \\
\text { rising stage larger than } \\
\text { those in declining } \\
\text { stage }\end{array}$} & \multirow{2}{*}{$\begin{array}{c}\text { Tianjin, Dalian, Shanghai, Nanjing, } \\
\text { Hangzhou, Xiamen, Jinan, Qingdao, } \\
\text { Guangzhou }\end{array}$} & $\begin{array}{l}\text { City with greatest } \\
\text { rank change }\end{array}$ & Guangzhou \\
\hline & & $\begin{array}{l}\text { City with least rank } \\
\text { change }\end{array}$ & Jinan \\
\hline \multirow{2}{*}{$\begin{array}{l}\text { Cities ranks of which } \\
\text { in housing prices } \\
\text { rising stage less than } \\
\text { those in declining } \\
\text { stage }\end{array}$} & \multirow{2}{*}{$\begin{array}{c}\text { Beijing, Shenyang, Changchun, } \\
\text { Haerbin, Ningbo, Chongqing, } \\
\text { Chengdu, Xi'an }\end{array}$} & $\begin{array}{l}\text { City with greatest } \\
\text { rank change }\end{array}$ & Ningbo \\
\hline & & $\begin{array}{l}\text { City with least rank } \\
\text { change }\end{array}$ & Beijing \\
\hline \multicolumn{2}{|c|}{$\begin{array}{l}\text { Cities ranks of which in housing prices rising stage equal to those } \\
\text { in declining stage }\end{array}$} & \multicolumn{2}{|c|}{ Wuhan, Shenzhen } \\
\hline
\end{tabular}

Table 3. Dating business cycle turning points

\begin{tabular}{|c|c|}
\hline Peak & Trough \\
\hline$\Delta_{i} y_{t} \geq 0 \quad i=1, \mathrm{~K}, 8$ & $\Delta_{i} y_{t} \leq 0 \quad i=1, \mathrm{~K}, 8$ \\
\hline$\Delta_{i} y_{t+i} \leq 0 \quad i=1, \mathrm{~K}, 8$ & $\Delta_{i} y_{t+i} \geq 0 \quad i=1, \mathrm{~K}, 8$ \\
\hline$\Delta_{i} y_{t+i}<0 \quad i=1, \mathrm{~K}, 2$ & $\Delta_{i} y_{t+i}>0 \quad i=1, \mathrm{~K}, 2$ \\
\hline
\end{tabular}

Table 4. Dating turning points in China's housing prices

\begin{tabular}{|c|c|c|c|}
\hline \multicolumn{2}{|r|}{ Peaks } & \multicolumn{2}{|r|}{ Troughs } \\
\hline $2006(4)$ & Guangzhou & $2008(3)$ & Guangzhou, Chongqing \\
\hline $2007(2)$ & Shenzhen & $2008(4)$ & $\begin{array}{l}\text { Shenzhen, Haerbin, Nanjing, } \\
\text { Xiamen, Chengdu, Shanghai, } \\
\text { Ningbo }\end{array}$ \\
\hline $2007(3)$ & $\begin{array}{l}\text { Beijing, Tianjin, Dalian, } \\
\text { Haerbin, Nanjing, Xiamen, } \\
\text { Qingdao, Chengdu }\end{array}$ & $2009(1)$ & $\begin{array}{c}\text { Beijing, Tianjin, Dalian, } \\
\text { Qingdao, Changchun, } \\
\text { Hangzhou, Wuhan, Xi'an, Jinan }\end{array}$ \\
\hline $2007(4)$ & $\begin{array}{l}\text { Changchun, Shanghai, } \\
\text { Hangzhou, Ningbo, Wuhan, } \\
\text { Chongqing, Xi'an, Shenyang }\end{array}$ & $2009(4)$ & Shenyang \\
\hline $2008(1)$ & Jinan & & \\
\hline
\end{tabular}

Nalioral Real Eslale Sellirs Price Irulex

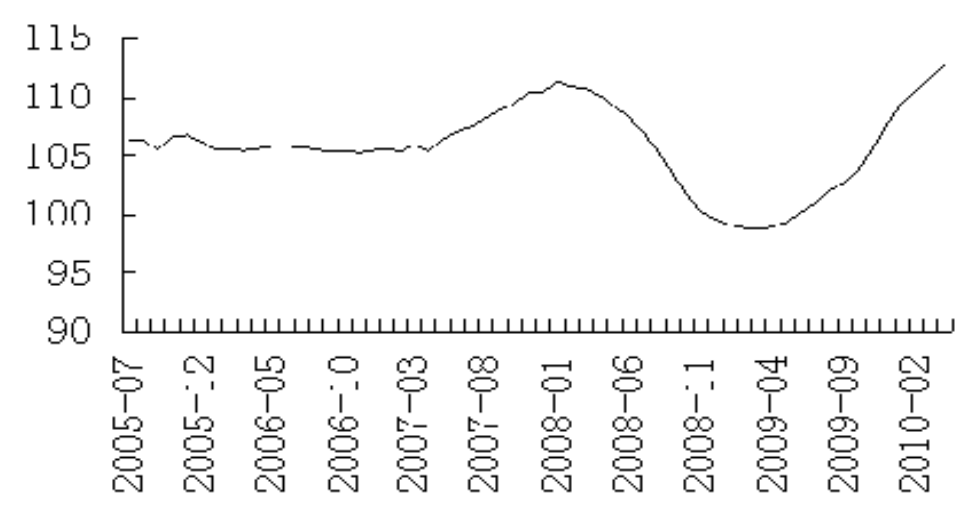

Figure 1 National real estate selling price index change chart 